Check for updates

Cite this: RSC Adv., 2017, 7, 54969

Received 30th September 2017 Accepted 25th November 2017

DOI: $10.1039 / c 7 r a 10805 b$

rsc.li/rsc-advances

\section{Activated biochar derived from pomelo peel as a high-capacity sorbent for removal of carbamazepine from aqueous solution $\uparrow$}

\author{
Dezhi Chen, (D) *a Shasha Xie, ${ }^{\text {a }}$ Caiqin Chen, ${ }^{a}$ Hongying Quan, ${ }^{\mathrm{b}} \mathrm{Li} \mathrm{Hua},{ }^{a}$ \\ Xubiao Luo (D) *a and Lin Guo ${ }^{\text {ac }}$
}

In recent years, the application of biochar to remove contaminants from aqueous solutions has become interesting due to favorable physical/chemical properties and abundant feedstocks. Herein, activated biochar was prepared by carbonization and further $\mathrm{KOH}$ activation using pomelo peel as a precursor. A series of characterization methods indicated that activation temperature can significantly influence the pore structure and surface chemistry of the obtained activated biochar. When used as a sorbent, the results showed that the adsorption isotherms of carbamazepine (CBZ) onto these activated biochars could be described well by Langmuir models. In addition, the kinetics of CBZ adsorption onto activated biochars were fitted well by pseudo-second-order kinetics and controlled by the intra-particle diffusion. The pore structure and surface functional groups could affect the adsorption of $C B Z$, resulting in the activated biochar of $\mathrm{AB}-700$ delivering a higher adsorption capacity of $\mathrm{CBZ}$ up to $286.5 \mathrm{mg} \mathrm{g}^{-1}$. Furthermore, different factors in the sorption process of $C B Z$ on $A B-700$, such as temperature, $\mathrm{pH}$, ionic strength and reusability, were studied in detail. The effects of solution temperature revealed that the adsorption processes were spontaneous and exothermic, and mainly physisorption. The presence of $\mathrm{Na}^{+}$ ions in solution showed almost no effect on the adsorption of CBZ. The reuse studies demonstrated that AB-700 showed $58.5 \%$ capacity retention at the $4^{\text {th }}$ cycle for the adsorption of CBZ. The effect of solution $\mathrm{pH}$ and surface analysis of biochar indicated that the adsorption of CBZ onto the activated biochar was mainly controlled by $\pi-\pi$ electron donor-acceptor interaction.

\section{Introduction}

Pharmaceuticals are widely used in the treatment and prevention of human and animal diseases. ${ }^{1}$ The annual consumption of pharmaceuticals per capita is estimated to be about $15 \mathrm{~g}$ in the world, and is $50-150 \mathrm{~g}$ in industrialized countries. ${ }^{2}$ The occurrence of these compounds in the aquatic environment has received growing attention in recent years due to their possible threats to human and animal health. ${ }^{3}$ Carbamazepine (CBZ) is a typical antiepileptic drug, and is widely used to treat epileptic seizures and nerve pain around the world with more than 1000 tons of annual consumption. ${ }^{2}$ It is estimated that the release

${ }^{a}$ Key Laboratory of Jiangxi Province for Persistent Pollutants Control and Resources Recycle, School of Environmental and Chemical Engineering, Nanchang Hangkong University, No. 696, Fenghe South Avenue, Nanchang, 330063, China. E-mail: chendz@nchu.edu.cn; luoxubiao@nchu.edu.cn

${ }^{b}$ School of Materials Science and Engineering, Nanchang Hangkong University, No. 696, Fenghe South Avenue, Nanchang 330063, China

${ }^{c}$ Key Laboratory of Bio-Inspired Smart Interfacial Science and Technology of Ministry of Education, School of Chemistry and Environment, Beihang University, No. 37 Xueyuan Road, Haidian District, Beijing 100191, China

$\dagger$ Electronic supplementary information (ESI) available. See DOI: 10.1039/c7ra10805b rate of $\mathrm{CBZ}$ into water bodies is around 30 tons per year. Previous research ${ }^{4}$ has revealed that CBZ may result in a decrease in the number of platelets, granulocytes, and leukocytes. Moreover, long term intake of CBZ could cause liver and kidney failure. $\mathrm{CBZ}$ is electrically neutral at typical $\mathrm{pH}$ values of drinking water and its $\log K_{\mathrm{ow}}=2.45$ shows that CBZ is relatively hydrophilic ${ }^{5}$ and does not easily attach to sludge and can stably remain in the aqueous phase. ${ }^{2}$ Furthermore, CBZ is resistant to biodegradation at low concentrations, ${ }^{2}$ and is very slowly degraded by sunlight. ${ }^{6}$ As a result, CBZ is one of the most commonly detected pharmaceuticals in the aquatic environment throughout the world, even in the raw water sources of drinking water treatment plants. ${ }^{7,8}$ However, the removal efficiency of CBZ from water in wastewaters treatment plants is lower than $10 \% .^{2}$ Therefore, it is necessary to develop new physical/chemical techniques for effective removal of CBZ from the water. Recently, adsorption process $^{9-11}$ and advanced oxidation technology ${ }^{12,13}$ have been evaluated for the treatment of CBZ-containing water because of its hydrophilicity and susceptibility to oxidative processes, respectively. Compared with the advanced oxidation methods with incomplete mineralization and sometimes the harmful transformation products,$^{14}$ the adsorption process is more attractive due to its easy 
handling process, high efficiency, and environmental friendliness. ${ }^{11,15,16}$ In addition, adsorption can be used to study the accumulation of organic micropollutants in the solid liquid interface.

Various adsorbents, such as carbonaceous nanomaterials, ${ }^{11,15,17}$ smectite clays, ${ }^{18}$ and imprinted polymers ${ }^{19}$ have been studied for the adsorption removal of CBZ from water. Due to their high specific surface area and high chemical/thermal stability, carbon nanomaterials as sorbents have shown high capacity and affinity for CBZ in aqueous solution. ${ }^{10,11,15,17,20}$ For example, carbon nanotubes have high adsorption capacity of CBZ up to $7910 \mathrm{mg} \mathrm{g}^{-1}$ (calculated from Polanyi-Mane model) due to their graphene surface and high specific surface area and micro/mesopore volume. ${ }^{\mathbf{1 6}}$ Graphene oxide exhibited high adsorption capacity of $215 \mathrm{mg} \mathrm{g}^{-1}$ for removal of CBZ from aqueous solution. ${ }^{\mathbf{1 5}}$ However, it is difficult to use these emerging carbon nanomaterials for removal of pharmaceuticals from water on a large scale because of their high price.

Recently, biochar, derived from waste biomass, has attracted great attention for purification of water sources due to their high porosity and capability of adsorbing different inorganic and organic pollutants. ${ }^{11,21,22}$ Jin et al. reported $^{23}$ that biochar derived from municipal solid wastes showed the adsorption capacity of $24.49 \mathrm{mg} \mathrm{g}^{-1}$ for As(v) from aqueous solution. Pine cone derived biochar by slow pyrolysis was used to removal of organic and inorganic pollutants from aqueous solution, and the Langmuir maximum adsorption capability was found to be 106.4 and $117.7 \mathrm{mg} \mathrm{g}^{-1}$ for methylene blue and nickel ions, respectively. ${ }^{24}$ The adsorption of pharmaceuticals in reclaimed water desalination concentrate using biochar was studied by Xu's group, ${ }^{25}$ and the results showed that the adsorption capacity of pharmaceuticals was affected by their physicochemical properties of biochar, as well as hydrophobicity, $\pi$-energy, and speciation of pharmaceuticals. To further enhance the adsorption performance of biochar for removal of contaminants in water, some effective approaches, including nanonization, surface modification, and activation of biochar, are attracting great interest..$^{11,21,22}$ To prepare biochar nanoparticles can effectively increase available sites for adsorption, which significantly increase the adsorption capacity and accelerate adsorption kinetics. ${ }^{\mathbf{1 1}}$ However, the nanoparticles are much difficult to recover from the water. The purpose of surface modification is, on the one hand, to enhance the adsorption capacity of sorbents, ${ }^{22}$ on the other hand, to provide the selectivity to the sorbents. ${ }^{26}$ Amino modification of biochar showed high adsorption capacity of copper ions from synthetic wastewater, which was five-folds of the pristine biochar. ${ }^{22}$ Chitosan-pyromellitic dianhydride modified biochar had strong selective adsorption of $\mathrm{Cu}(\mathrm{II}){ }^{26}$ However, the surface modification of biochar generally needs cumbersome steps, which inhibits its practical application in treatment of wastewater. Therefore, the activation is a more suitable and efficient method to improve the adsorption performance of biochar in comparison of the nanonization and surface modification. The activation could significantly increase the specific surface area and pore volume of biochar,

which would obviously increase the available adsorption sites and promote the diffusion rate of contaminants. ${ }^{21}$ Therefore, in this study, activated biochar was prepared using waste pomelo peel as precursor by a simple pyrolysis method and further $\mathrm{KOH}$ activation. The morphology, structure, and surface chemistry of the pomelo peel-derived activated biochar were characterized, respectively. The adsorption behavior of pharmaceutical CBZ on the produced biochar from aqueous phase was investigated by the analysis of adsorption isotherms, kinetics and thermodynamics. In addition, the effect of solution $\mathrm{pH}$, ion strength on the adsorption capacity was studied. Finally, the adsorption mechanism of CBZ on the obtained biochar was discussed.

\section{Materials and methods}

\subsection{Materials}

Waste pomelo peel was obtained from the local fruit shop. Anhydrous ethanol, potassium hydroxide and concentrated hydrochloric acid (37\%) were purchased from Xilong Scientific Co., Ltd (China). CBZ was purchased from Aladdin (Shanghai, China), and its physicochemical properties are listed in Table 1. All chemicals were A.R. grade and used without further purification.

\subsection{Synthesis of biochar and activated biochar}

In a typical process, biochar was prepared by carbonization of pomelo peel at $400{ }^{\circ} \mathrm{C}$ for $1 \mathrm{~h}$ with a heating rate of $5{ }^{\circ} \mathrm{C} \mathrm{min}{ }^{-1}$ under $\mathrm{N}_{2}$ flow of $100 \mathrm{~cm}^{3} \mathrm{~min}^{-1}$. After then, the pomelo peelderived biochar was mixed with the same amount of $\mathrm{KOH}$ in aqueous solution. After drying at $80{ }^{\circ} \mathrm{C}$ for $24 \mathrm{~h}$, the obtained solid samples were placed in a nickel crucible and further activated at pre-set temperature $\left(600,700,800,900{ }^{\circ} \mathrm{C}\right)$ for $2 \mathrm{~h}$ with a heating rate of $5{ }^{\circ} \mathrm{C} \min ^{-1}$ under the protection of $\mathrm{N}_{2}$ atmosphere. Finally, the as-obtained biochar (B-400) and activated biochar samples (AB-600, AB-700, AB-800 and AB-900) were washed with $1 \mathrm{M} \mathrm{HCl}$ to remove any inorganic

Table 1 Physiochemical properties of CBZ

CBZ

Chemical structure

Usage

Formula

CAS number

MW $\left(\mathrm{g} \mathrm{mol}^{-1}\right)$

$\mathrm{MV}\left(\mathrm{cm}^{3} \mathrm{~mol}^{-1}\right)$

Water solubility $\left(\mathrm{mg} \mathrm{L}^{-1}\right)$

$\mathrm{p} K_{\mathrm{a}}$

$\log K_{\mathrm{ow}}$

Diameter $(\AA)$

Dipole moment (debye)

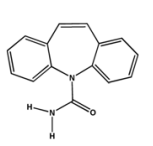

Antiepileptic $\mathrm{C}_{15} \mathrm{H}_{12} \mathrm{~N}_{2} \mathrm{O}$ 298-46-4

236.27

186.5

17.7

13.9

2.45

7.3

3.66 
impurities, and then washed thoroughly with distilled water until $\mathrm{pH} \approx 7$ and dried at $80{ }^{\circ} \mathrm{C}$ for $24 \mathrm{~h}$.

\subsection{Characterization}

Phase and morphology of the as-prepared biochar were analyzed by Bruker X-ray diffraction (XRD, D8 Advanced) at a scan rate of $4^{\circ} \mathrm{min}^{-1}$, FEI scanning electron microscope (SEM, Quanta 450) at $10 \mathrm{kV}$, and FEI transmission electron microscope (Talos F200X) at $100 \mathrm{kV}$. The specific surface areas and pore size distributions were studied by nitrogen adsorption-desorption isotherms, which were obtained on a TriStar II 3020 surface area \& pore size analyzer (Micromeritics). The surface zeta potential of biochar was measured by Malvern Nano-ZS90 Zetaszier. The surface chemistry of biochar was studied by X-ray photoelectron spectra (XPS) on an Axis Ultra (Kratos) XPS spectrometer. Thermogravimetric (TG) curve was obtained on a TG analyzer (Q600, TA Instruments) under nitrogen $\left(100 \mathrm{~cm}^{3} \mathrm{~min}^{-1}\right)$ with the temperature rate of $5{ }^{\circ} \mathrm{C} \mathrm{min}^{-1}$.

\subsection{Adsorption isotherm}

Sorption isotherms were obtained as followed. $10 \mathrm{mg}$ of sorbent was added into the conical flasks with $50 \mathrm{~mL} \mathrm{CBZ}$ aqueous solution with the concentration $\left(C_{0}\right)$ from $\left(10\right.$ to $\left.100 \mathrm{mg} \mathrm{L}{ }^{-1}\right)$, then these flasks were put into an orbital shaker at $180 \mathrm{rpm}$ under pre-set temperature for $24 \mathrm{~h}$. The effect of $\mathrm{pH}$ on $\mathrm{CBZ}$ adsorption was studied by varying the $\mathrm{pH}$ of $\mathrm{CBZ}$ solution (100 $\left.\mathrm{mg} \mathrm{L}^{-1}\right)$ in the range of 2.0 to 12.0 using $\mathrm{HCl}\left(0.1 \mathrm{~mol} \mathrm{~L}^{-1}\right)$ and $\mathrm{NaOH}\left(0.1 \mathrm{~mol} \mathrm{~L}^{-1}\right)$ solutions. After reached adsorption equilibration, the sorbent was removed using $0.22 \mu \mathrm{m}$ membrane filters, and then the residual CBZ in solution was examined by UV spectrophotometer (Hitachi U-3010/3310) at $285 \mathrm{~nm}$.

The quantity of organic contaminants absorbed on per unit mass of sorbent was calculated by the following equation:

$$
Q_{t}=Q_{\mathrm{m}}=Q_{\mathrm{e}}=\left(C_{0}-C_{t}\right) \frac{V}{m}
$$

The maximum adsorbed amount, $Q_{\mathrm{m}}\left(\mathrm{mg} \mathrm{g}^{-1}\right)$, the amount adsorbed at the equilibrium, $Q_{\mathrm{e}}\left(\mathrm{mg}^{-1}\right)$, and the adsorbed amount of CBZ at time $t$ onto APPC, $Q_{t}\left(\mathrm{mg} \mathrm{g}^{-1}\right)$, were calculated by the equation, where $C_{0}, C_{\mathrm{e}}$ and $C_{t}\left(\mathrm{mg} \mathrm{L}^{-1}\right)$ are the initial concentrations of $\mathrm{CBZ}$ at the equilibrium and at the time $t$ respectively. $V$ is the volume of the solution, and $m$ is the weight of sorbent.

\subsection{Adsorption kinetic}

The adsorption kinetics of CBZ on biochar were revealed as followed. $200 \mathrm{mg}$ of biochar was added into a $1000 \mathrm{~mL} \mathrm{CBZ}$ solution $\left(100 \mathrm{mg} \mathrm{L}^{-1}\right)$ with constant magnetic stirring at $25{ }^{\circ} \mathrm{C}$. Then, $1.5 \mathrm{~mL}$ of the solution sample was collected at a predetermined time interval and immediately filtered to remove the sorbent with a $0.22 \mu \mathrm{m}$ membrane filters. The concentrations of CBZ in aqueous solution were analyzed by UV spectrophotometer at $285 \mathrm{~nm}$, respectively.

\subsection{Effect of ion strength}

$10 \mathrm{mg}$ of sorbent of AB-700 was added into the conical flasks with $50 \mathrm{~mL} 100 \mathrm{mg} \mathrm{L} \mathrm{CBZ}$ solution containing $\mathrm{Na}^{+}$ions with the concentration from 0.005 to $0.02 \mathrm{M}$, which placed into the temperature-controlled shaker at $25{ }^{\circ} \mathrm{C}$ shaken at $180 \mathrm{rpm}$ for $48 \mathrm{~h}$. After reached adsorption equilibration, the sorbent was removed using $0.22 \mu \mathrm{m}$ membrane filters, and then the residual CBZ in solution was examined by UV spectrophotometer (Hitachi U-3010/3310) at $285 \mathrm{~nm}$.

\subsection{Reuse of sorbent}

$200 \mathrm{mg}$ adsorbent of $\mathrm{AB}-700$ was added into the beaker containing $1 \mathrm{~L} \mathrm{CBZ}$ solution $\left(100 \mathrm{mg} \mathrm{L}^{-1}\right.$ ) under constant magnetic stirring at $25{ }^{\circ} \mathrm{C}$ for $24 \mathrm{~h}$. After the adsorption equilibrium, the adsorbent was removed by a $0.22 \mu \mathrm{m}$ filters, and the concentrations of residual CBZ in the solution were analyzed by UV spectrophotometer at $285 \mathrm{~nm}$, then, the recycled black powder was calcined at $350{ }^{\circ} \mathrm{C}$ under nitrogen, the TG curve (Fig. S1 $\dagger$ ) shows that $\mathrm{CBZ}$ is almost completely decomposed when the temperature reaches about $330{ }^{\circ} \mathrm{C}$. This whole process was repeated for three times.

\section{Results and discussion}

\subsection{Characterization}

Fig. S $2 \uparrow$ shows typical SEM images of B-400 and AB-800 biochar from pomelo peel. As we can see, it is almost no difference in the morphology for the pristine biochar and activated biochar. Both are micro-sized particles. Fig. 1 shows the XRD patterns of pristine and activated biochar from pomelo peel. Pristine biochar and activated biochar have two bread-like peaks at about $2 \theta=24$ and $42^{\circ}$, which indicates the characteristic of amorphous. ${ }^{27}$ The diffraction intensity of activated biochar in the low angle region is relatively large, indicating that they possess abundant micropores. ${ }^{28}$

The nitrogen adsorption-desorption isotherms and the poresize distribution of as-prepared biochar samples are presented in Fig. 2a and b, respectively. The isotherm of B-400 is typical type IV with $\mathrm{H} 4$ hysteresis loops, which indicates mesoporous structure. It mainly comes from the removal of inorganic impurities, such as $\mathrm{SiO}_{2}$. For the AB-600, AB-700, AB-800 and AB-900, the nitrogen gas adsorption increased quickly at low pressure area $\left(P / P_{0}<0.05\right)$ and then reached to adsorption

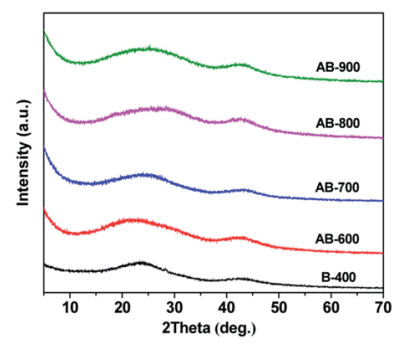

Fig. 1 XRD patterns of pristine biochar and activated biochar at 600 , 700,800 and $900{ }^{\circ} \mathrm{C}$. 

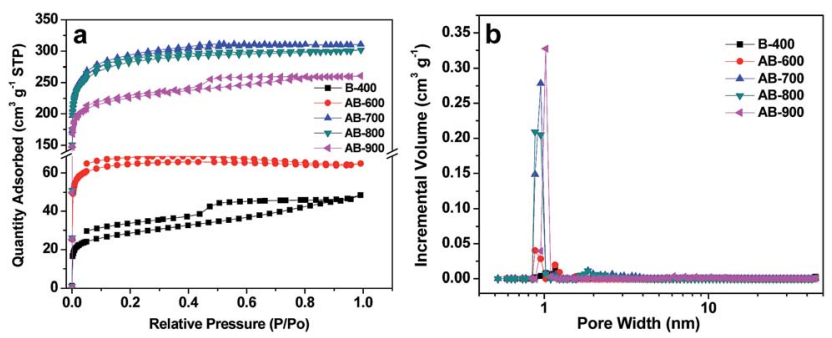

Fig. 2 (a) $\mathrm{N}_{2}$ adsorption-desorption isotherms and (b) pore-size distribution of as-prepared biochar samples.

plateaus, indicating the existence of main microporous. The increasing hysteresis loops in AB-700, AB-800 and AB-900 at the medium pressure phase indicate that the mesopores were produced and grown in number with the increasing activation temperature. The specific surface areas and pore volumes of pristine biochar and activated biochar, calculated from the corresponding nitrogen adsorption-desorption isotherms using the Brunauer-Emmet-Teller (BET) model and density functional theory (DFT), respectively, are shown in Table 2.

Under the protection of inert gas, there will be chemical reaction between $\mathrm{KOH}$ and biochar at low temperature of 400$600{ }^{\circ} \mathrm{C}$,

$$
4 \mathrm{KOH}+\left(-\mathrm{CH}_{2}\right) \rightarrow \mathrm{K}_{2} \mathrm{CO}_{3}+\mathrm{K}_{2} \mathrm{O}+3 \mathrm{H}_{2}
$$

In the above process, the micropores will appear. With the increasing of temperature, $\mathrm{KOH}$ is completely consumed and the resulting $\mathrm{K}_{2} \mathrm{CO}_{3}$ and $\mathrm{K}_{2} \mathrm{O}$ can further activate the carbon material by the following reaction:

$$
\begin{gathered}
\mathrm{K}_{2} \mathrm{CO}_{3}+2 \mathrm{C} \rightarrow 2 \mathrm{~K}+3 \mathrm{CO} \\
\mathrm{K}_{2} \mathrm{O}+\mathrm{C} \rightarrow 2 \mathrm{~K}+\mathrm{CO}
\end{gathered}
$$

At high temperature, the $\mathrm{K}_{2} \mathrm{CO}_{3}$ and $\mathrm{K}_{2} \mathrm{O}$ were reduced to elemental potassium by carbon. Meanwhile, the consumption of carbon can improve pore structure of our biochar. If the activation temperature is higher than the boiling point of potassium, there will create new pores. In the activation of our biochar, the specific surface area $\left(S_{\mathrm{BET}}=904.1 \mathrm{~m}^{2} \mathrm{~g}^{-1}\right)$ and pore volume $\left(0.506 \mathrm{~cm}^{3} \mathrm{~g}^{-1}\right)$ of $\mathrm{AB}-700$ is highest in all activated

Table 2 Physical properties of the as-prepared biochars

\begin{tabular}{lclllll}
\hline & & \multicolumn{2}{l}{$\begin{array}{l}\text { Pore diameter } \\
(\mathrm{nm})\end{array}$} & & \multicolumn{2}{l}{$\begin{array}{l}\text { Pore volume } \\
\left(\mathrm{cm}^{3} \mathrm{~g}^{-1}\right)\end{array}$} \\
& & & & & & \\
Sample & $S_{\text {BET }}\left(\mathrm{m}^{2} \mathrm{~g}^{-1}\right)$ & Micro & Meso & & Total & Micro \\
\hline B-400 & 94.1 & 1.17 & 3.42 & & 0.071 & 0.035 \\
AB-600 & 198.0 & 0.87 & & 0.104 & 0.103 \\
AB-700 & 904.1 & 0.95 & 2.34 & & 0.506 & 0.464 \\
AB-800 & 874.4 & 0.95 & 6.10 & & 0.487 & 0.460 \\
AB-900 & 702.2 & 1.02 & 3.42 & 0.397 & 0.370
\end{tabular}

biochar samples, which indicates that the $700{ }^{\circ} \mathrm{C}$ is suitable for the activation of pomelo peel-derived biochar. When the activation temperature increased to $800^{\circ} \mathrm{C}$, the specific surface area and pore volume slightly decreased to $874.4 \mathrm{~m}^{2} \mathrm{~g}^{-1}$ and $0.487 \mathrm{~cm}^{3} \mathrm{~g}^{-1}$, respectively. When the temperature was increased to $900{ }^{\circ} \mathrm{C}$, the activation of biochar would carry out more thoroughly. The pore-size of AB-900 was increased and more mesopore was produced, which caused the decrease of specific surface area and pore volume to $702.2 \mathrm{~m}^{2} \mathrm{~g}^{-1}$ and $0.397 \mathrm{~cm}^{3} \mathrm{~g}^{-1}$, respectively.

To further observe the microstructure, the typical TEM and high-resolution (HR) TEM images of as-prepared AB-700 are presented in Fig. 3. From the TEM image shown in Fig. 3a, carbon submicron particles can be clearly observed. As shown in Fig. 3b, we can see the disordered texture of the obtained carbon material. No evident lattice fringe can be found in the HRTEM (Fig. 3c). The selected-area electron diffraction (SAED) pattern in Fig. 3d suggests the amorphous feature of our as prepared carbon material. Meanwhile, the typical TEM images of AB-600 are shown in Fig. S3† for comparison. It can be seen from the Fig. 3 and $\mathrm{S} 3 \uparrow$ that the difference of microstructure between AB-700 and AB-600 is not obvious, even though the significant difference of specific area and pore volume from $\mathrm{N}_{2}$ adsorption-desorption isotherms presented in Fig. 2.

The surface chemistry of activated biochar was important for their adsorption performance. The XPS spectra of AB-600, AB$700, A B-800$ and AB-900 are shown in Fig. 4. We can see that there have carbon, oxygen, and nitrogen on the surface of activated biochar, and the atomic concentrates are listed in Table S1. $\dagger$ It indicates that the concentrates of oxygen and nitrogen in the surface of activated biochar decrease with the increase of activation temperature.

\subsection{Adsorption isotherms}

The adsorption isotherm describes the relationship between the residual concentration of the adsorbate in the liquid phase
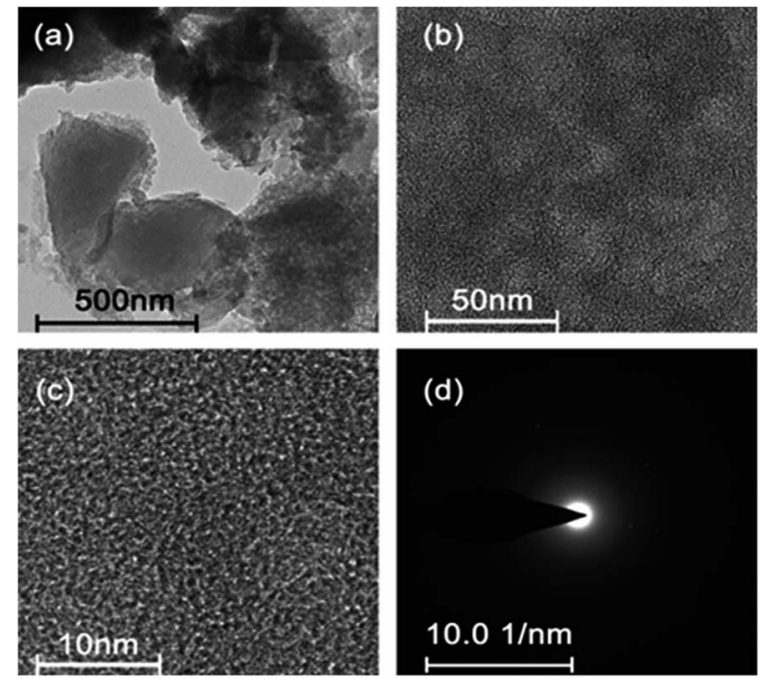

Fig. 3 Typical (a) TEM, (b, c) HRTEM images and (d) SAED of AB-700. 


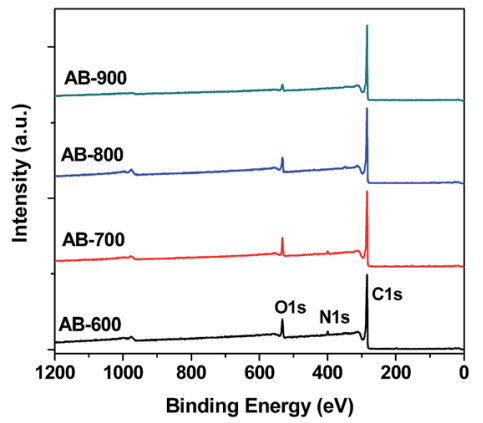

Fig. 4 XPS spectra of activated biochar.

and the adsorption concentration on the surface of the adsorbent at a certain temperature. The adsorption isotherm is important for determining the adsorption behavior of an adsorbent. Fig. 5a shows the adsorption isotherms of CBZ onto produced biochar at $298 \mathrm{~K}$ and $\mathrm{pH}=4.4$. For the sorbents of $\mathrm{B}$ 400 and AB-600, with the increase of CBZ initial concentration, the adsorption capacities increased gradually, and then the increasing trend was gradually slow, and the adsorption was stable, indicating adsorption saturation finally. In comparison of $\mathrm{B}-400$ and $\mathrm{AB}-600$, the adsorption capacities of $\mathrm{CBZ}$ onto $\mathrm{AB}-$ $700, A B-800$ and $A B-900$ increased rapidly with the increase of the CBZ initial concentration. Then, the adsorption of CBZ on AB-700, AB-800 and AB-900 reached adsorption equilibrium. At low concentrations, the slope of the curve is large, indicating that there are many active sites on the surface of the activated biochar. When the concentration is increased, the curve tends to level.

To further explore the interaction of adsorbate with adsorbents and the structural characteristics of adsorption layer, three isothermal models including Langmuir, Freundlich, and Dubinin-Radusckevich (D-R) were used to fit the adsorption data, and the corresponding equations are given:
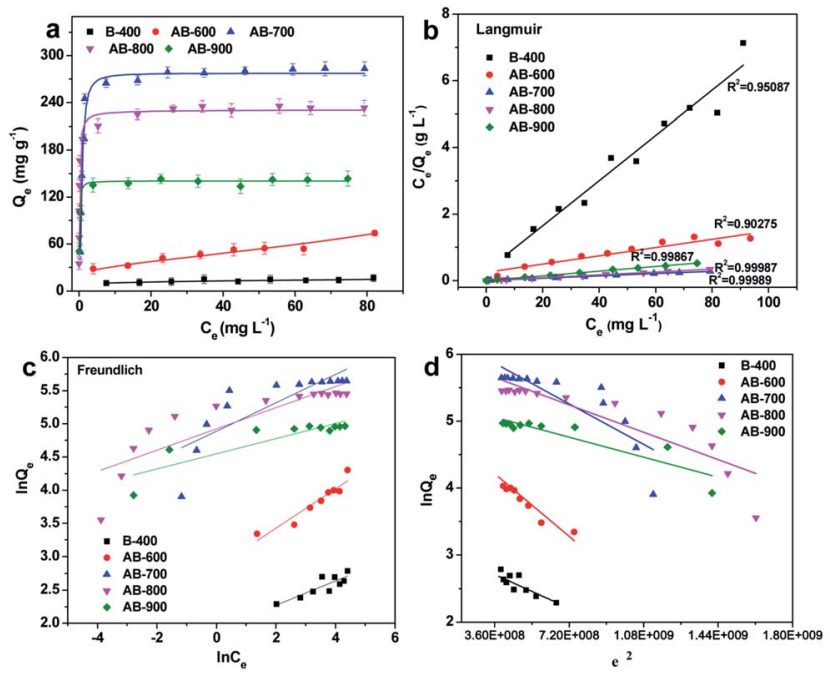

Fig. 5 (a) Adsorption isotherms of CBZ on as-prepared biochar samples, and the corresponding (b) Langmuir, (c) Freundlich and (d) $\mathrm{D}-\mathrm{R}$ linear fitting results.
Langmuir model:

$$
\begin{gathered}
\frac{C_{\mathrm{e}}}{Q_{\mathrm{e}}}=\frac{C_{\mathrm{e}}}{Q_{\mathrm{m}}}+\frac{1}{Q_{\mathrm{m}} b} \\
R_{\mathrm{L}}=\frac{1}{1+b C_{0}}
\end{gathered}
$$

Freundlich model:

$$
\ln Q_{\mathrm{e}}=\frac{\ln C_{\mathrm{e}}}{n}+\ln K_{\mathrm{f}}
$$

D-R model:

$$
\begin{gathered}
\ln Q_{\mathrm{e}}=\ln Q_{\mathrm{m}}-K_{\mathrm{DR}} \varepsilon^{2} \\
\varepsilon=R T \ln \left(1+\frac{1}{C_{\mathrm{e}}}\right) \\
E=\left(2 K_{\mathrm{DR}}\right)^{-1 / 2}
\end{gathered}
$$

where $Q_{\mathrm{m}}\left(\mathrm{mg} \mathrm{g}^{-1}\right)$ is the maximum capacity of $\mathrm{CBZ}, Q_{\mathrm{e}}\left(\mathrm{mg} \mathrm{g}^{-1}\right)$ is the equilibrium adsorption amount at $\mathrm{CBZ}$ equilibrium concentration $C_{\mathrm{e}}\left(\mathrm{mg} \mathrm{L}^{-1}\right), b\left(\mathrm{~L} \mathrm{mg}^{-1}\right)$ is the Langmuir constant and $C_{0}\left(\mathrm{mg} \mathrm{L}^{-1}\right)$ is the initial concentration of CBZ, $R_{\mathrm{L}}$ is the separation factor (or balance coefficient). $K_{\mathrm{f}}$ is the Freundlich coefficient constant and $n$ is the linearity index; $K_{\mathrm{DR}}$ $\left(\left(\mathrm{mol} \mathrm{kJ}^{-1}\right)^{2}\right)$ is the activity coefficient related to the adsorption energy; $\varepsilon$ is the Polanyi potential; $R$ is the ideal gas constant $\left(8.314 \mathrm{~J} \mathrm{~mol}^{-1} \mathrm{~K}^{-1}\right), T(\mathrm{~K})$ is the absolute temperature and $E$ $\left(\mathrm{kJ} \mathrm{mol}^{-1}\right)$ is the mean adsorption energy.

The linear fitting results of Langmuir, Freundlich and D-R models are shown in Fig. 5b, c and d, respectively. The parameters of the Langmuir, Freundlich and D-R models were calculated and were given in Table 3. The results show that the adsorption isotherms of CBZ onto produced biochar fitted well with Langmuir model, suggesting that the adsorption of CBZ can be recognized to be a monolayer adsorption process. The maximum adsorption capacity $\left(Q_{\mathrm{m}}\right)$ of $\mathrm{CBZ}$ on the nonactivated biochar and activated biochar active at $298 \mathrm{~K}$ is $14.75,80.64$, 286.5, 234.2, and $142.5 \mathrm{mg} \mathrm{g}^{-1}$ for B-400, AB-600, AB-700, AB800 , and AB-900, respectively.

The hypothesis of Langmuir model is that adsorption is the single layer adsorption, all adsorption sites are the same, and the adsorption particles are completely independent. ${ }^{29}$ The essential feature of Langmuir isotherm is $R_{\mathrm{L}}$, which is a dimensionless equilibrium parameter and can effectively reflect the characteristics of the isotherm and the nature of adsorption. ${ }^{30} R_{\mathrm{L}}=0$ indicate that adsorption is irreversible. $R_{\mathrm{L}}$ is between 0 and 1 , suggesting favorable adsorption for all the initial concentrations and the temperatures. $R_{\mathrm{L}}=1$ shows that the adsorption is reversible, and the adsorption isotherm is linear. Otherwise, a value of $R_{\mathrm{L}}>1$ indicates unfavorable adsorption. Herein, all $R_{\mathrm{L}}$ in our experiment is between 0 and 1 , indicating that the CBZ adsorption on our as-prepared biochar is favorable. 
Table 3 The parameters of Langmuir, Freundlich and D-R for CBZ adsorption on these as-prepared biochar sorbents

\begin{tabular}{|c|c|c|c|c|c|c|c|c|c|}
\hline Sample & \multicolumn{3}{|c|}{ Langmuir } & \multicolumn{3}{|c|}{ Freundlich } & \multicolumn{3}{|c|}{ Duninin-Radushkevich } \\
\hline AB-600 & 80.64 & 0.0497 & 0.903 & 110.4 & 4.564 & 0.682 & 2.60 & 13.864 & 0.868 \\
\hline AB-700 & 286.5 & 1.212 & 0.999 & 132.8 & 4.669 & 0.822 & 1.69 & 17.219 & 0.645 \\
\hline AB-800 & 234.2 & 5.393 & 0.999 & 139.2 & 6.186 & 0.859 & 1.14 & 20.972 & 0.776 \\
\hline
\end{tabular}

Table 4 Comparison of maximum adsorption capacities $\left(Q_{m}\right)$ of CBZ on different adsorbents

\begin{tabular}{lll}
\hline Adsorbents & $Q_{\mathrm{m}}\left(\mathrm{mg} \mathrm{g}^{-1}\right)$ & References \\
\hline $\begin{array}{lll}\text { Magnetic nanocomposite of } \\
\text { activated carbon }\left(\mathrm{Fe}_{3} \mathrm{O}_{4} / \mathrm{C}\right)\end{array}$ & 182.9 & 32 \\
Activated palm kernel shell & & \\
Activated carbon $(\mathrm{AC}) / \mathrm{Fe}_{3} \mathrm{O}_{4}$ & 170.1 & 33 \\
Magnetic biochar/ $/ \mathrm{Fe}_{3} \mathrm{O}_{4}$ & 45.3 & 34 \\
MWCNT & 62.7 & 34 \\
Expanded graphite & 108 & 35 \\
MOF-derived magnetic porous carbon & 43.54 & 36 \\
Peanut shell-biochars & 37.918 & 37 \\
SWCNT & 189 & 38 \\
Pine-wood nanobiochar & 116 & 39 \\
Biomass activated carbon & 286.5 & 11 \\
& &
\end{tabular}

The superb adsorption capacity of the activated biochar could be due to the relatively large specific surface area, large pore volume and mesoporous structure, providing many exposed active sites and accessible diffusion pathways for the transportation of molecules. The adsorption capacity of AB-700 is up to $286.5 \mathrm{mg} \mathrm{g}^{-1}$, which is much higher than other biochar and carbonaceous nanomaterials (see Table 4). Fig. S4† shows the relationship of pore structure and the adsorption capacity. It can be observed that the $Q_{\mathrm{m}}$ of CBZ increases with the increasing specific surface area and pore volume (Fig. S4a $\dagger$ ), which indicates that the higher specific surface area and pore volume can provide more effective adsorption sites for CBZ. In addition, the utilization efficiency of pore, presented in Fig. S4b, $\uparrow$ shows a triangular shape, indicating that the pore structure of biochar could affect the adsorption of CBZ. The highest utilization efficiency of AB600 could be mainly attributed to its smallest pore-size $(0.87$ $\mathrm{nm}$ ) in all sorbents, which is consistent with the previous studies that the smaller pore has more active in physical adsorption and they create high-energy physical adsorption centres. ${ }^{\mathbf{9}, 31}$ Although the pore-size and $V_{\text {micro }}$ of $\mathrm{AB}-700$ and $\mathrm{AB}-800$ are almost the same, the adsorption capacity $\left(286.5 \mathrm{mg} \mathrm{g}^{-1}\right)$ of AB-700 is obviously higher than that of AB-800 (234.2 $\left.\mathrm{mg} \mathrm{g}^{-1}\right)$. It implies that the mesopore and the surface functional groups presented in the biochar are important in the adsorption of CBZ.

\subsection{Adsorption kinetics}

Adsorption kinetic is generally used to estimate the rate of adsorption and provides valuable insights for the adsorption mechanism. ${ }^{26}$ Fig. 6a shows the influence of the contact time on the adsorption of CBZ onto pristine and activated biochars derived from pomelo peel, respectively. It can be observed that the adsorption amount of CBZ on the as-prepared biochars increased rapidly in the initial dozens of minutes, and then slowed down until the adsorption reached equilibrium with $6 \mathrm{~h}$. It indicated that the adsorption of CBZ occurred in two steps, including rapid adsorption of CBZ to the surface of biochars and slow diffusion in the biochars interior. The fast adsorption rates in the initial step could be attributed to the surface physical sorption ( $\pi-\pi$ interactions), which is facilitated by lots of active sites at the surface of the biochars and the accessible diffusion pathway in the mesoporous domains. When these surface-active sites were occupied, the adsorption process slowed down and the adsorption rates were limited by the diffusion of CBZ molecules from liquid to the inner-pores of the biochar due to the longer diffusion distance and the larger diffusion resistance. In addition, the first step occurred within 30, 50, 80, 120 and $150 \mathrm{~min}$ for B-400, AB-600, AB-900, AB-800 and AB-700, respectively, which could be attributed to the surface properties of biochar. It indicates that the effective surface adsorption sites for CBZ follow the order of AB-700 $>$ AB-800 $>$ AB-900 $>$ AB-600 > B-400. The more sites could uptake more $\mathrm{CBZ}$ onto the surface of sorbent in the first step, which required more time.
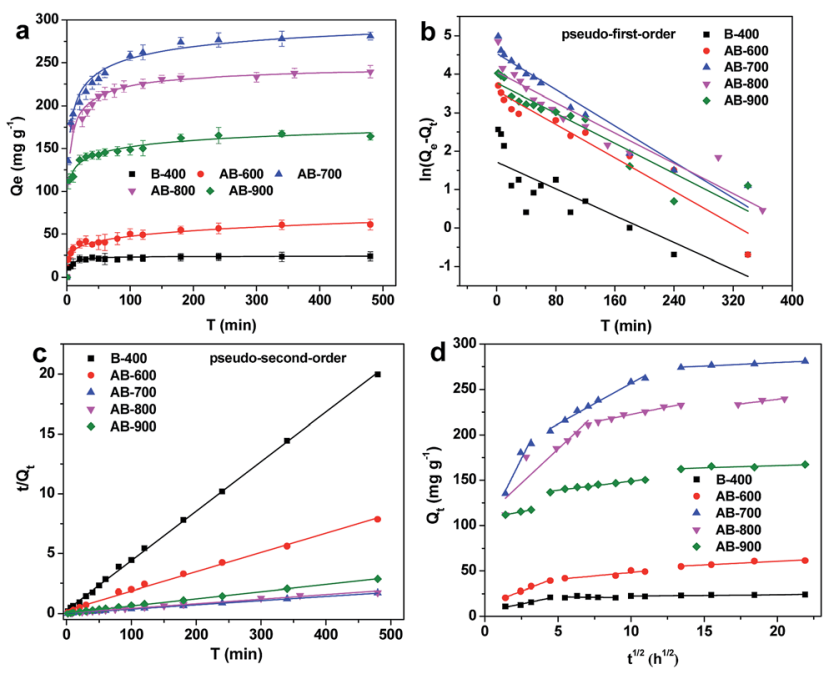

Fig. 6 (a) Adsorption kinetics of CBZ on the as-prepared biochars at $298 \mathrm{~K}$, and the corresponding linear fitting results by (b) pseudo-firstorder, (c) pseudo-second-order and (d) intra-particle diffusion model. 
Table 5 The parameters of kinetics for CBZ adsorption onto as-prepared biochars

\begin{tabular}{|c|c|c|c|c|c|c|c|}
\hline Sorbent & \multicolumn{4}{|l|}{ Pseudo-first-order } & \multicolumn{3}{|l|}{ Pseudo-second-order } \\
\hline $600^{\circ} \mathrm{C}$ & 10.88 & 35.511 & 61.122 & 0.932 & 0.958 & 62.227 & 0.995 \\
\hline $700{ }^{\circ} \mathrm{C}$ & 11.74 & 96.529 & 281.062 & 0.945 & 0.440 & 284.900 & 0.999 \\
\hline $800{ }^{\circ} \mathrm{C}$ & 9.86 & 57.529 & 339.370 & 0.879 & 0.281 & 261.096 & 0.990 \\
\hline
\end{tabular}

The pseudo-first-order and pseudo-second-order kinetic models were applied to fit the experimental data, and the corresponding equations were listed as follows:

Pseudo-first-order model:

$$
\ln \left(Q_{\mathrm{e}}-Q_{t}\right)=\ln Q_{\mathrm{e}}-k_{1} t
$$

Pseudo-second-order model:

$$
\frac{t}{Q_{t}}=\frac{1}{k_{2} Q_{\mathrm{e}}{ }^{2}}+\frac{t}{Q_{\mathrm{e}}}
$$

where $Q_{\mathrm{e}}\left(\mathrm{mg} \mathrm{g}^{-1}\right)$ and $Q_{t}\left(\mathrm{mg} \mathrm{g}^{-1}\right)$ are the amounts of CBZ adsorbed onto the biochars at the equilibrium time and time $t$ (min), respectively, $k_{1}\left(\min ^{-1}\right)$ and $k_{2}\left(\mathrm{~g} \mathrm{mg}^{-1} \min ^{-1}\right)$ are the rate constants for the pseudo-first-order and pseudo-secondorder kinetics, respectively. The linear fitting results of pseudo-first-order and pseudo-second-order kinetic models are shown in Fig. 6b and c, respectively. The corresponding kinetic parameters and the correlation coefficients are summarized in Table 5. The correlation coefficient $\left(R^{2}\right)$ of the pseudo-secondorder kinetic by the pseudo-second-order model, which suggests that the adsorption process of CBZ involve chemisorption related to valence forces through electron exchange or sharing.

To further understand the adsorption kinetic of CBZ onto asprepared biochars, the intra-particle diffusion model was used to fit the adsorption data, and the model equation is shown as follows: ${ }^{40}$

$$
Q_{t}=k_{\mathrm{d}} t^{1 / 2}+C
$$

where $Q_{t}\left(\mathrm{mg} \mathrm{g}^{-1}\right)$ is the adsorbate loading on the solid phase at time $t, k_{\mathrm{d}}\left(\mathrm{mg} \mathrm{g}^{-1} \mathrm{~min}^{1 / 2}\right)$ is the intra-particle diffusion rate constant, and $C\left(\mathrm{mg} \mathrm{g}^{-1}\right)$ is the constant that is proportional to the thickness of boundary layer; the larger the value of $C$, the greater the boundary layer thickness. If the plot of $t^{1 / 2} v s . Q_{t}$ is a straight line, the particle diffusion controls the adsorption process. If not, it means that more than one process controls the adsorption process. Fig. $6 \mathrm{~d}$ and Table 6 show the kinetic data fitted on the intra-particle diffusion model for the biochar samples. All biochar samples can be divided into three straight lines. The first portion of the straight line represents the diffusion of CBZ from the boundary to the adsorbent surface, and the high $k_{\mathrm{d} 1}$ indicates that the diffusion of CBZ from the boundary to the adsorbent surface is fast because the concentration of adsorbate in solution is high and only a little CBZ was adsorbed onto the surfaces of sorbent at the beginning of the adsorption. The high concentration difference could promote the diffusion of the adsorbent molecules to the outer surface of the solid adsorbent and accelerate the process of external mass transfer. The second portion is the pore diffusion and adsorption, where CBZ is transported to the pores of biochar and adsorbed on the inner surface of sorbent. The smaller $k_{\mathrm{d} 2}$ illustrates the slow process of diffusion of the adsorbate molecules within the particles, and indicates that the diffusion particle limits the rate of the entire adsorption process as one of the major rate-limiting for the adsorption of CBZ onto biochar. The third portion corresponds to the adsorption equilibrium. The very small $k_{\mathrm{d} 3}$ shows that the diffusion rate in this stage is extremely slow, which can be attributed to the decreased poresize, increased electrostatic repulsion, and reduced driving force.

\subsection{Thermodynamic analysis}

Temperature is an important factor for adsorption process. The effect of temperature on CBZ adsorption was studied, and the adsorption isotherms of CBZ onto AB-700 at 298, 308 and $318 \mathrm{~K}$ are shown in Fig. 7a. As we can see, the adsorption capacity $\left(Q_{\mathrm{e}}\right)$ of $\mathrm{CBZ}$ onto $\mathrm{AB}-700$ increased with increasing temperature,

Table 6 Intra-particle diffusion model constants for CBZ adsorption onto as-prepared biochars

\begin{tabular}{lcccccrrrr}
\hline \multicolumn{7}{c}{ Intra-particle diffusion model } \\
\cline { 2 - 9 } Sample & $k_{\mathrm{d} 1}$ & $C_{1}$ & $R_{12}$ & $k_{\mathrm{d} 2}$ & $C_{2}$ & $R_{22}$ & $k_{\mathrm{d} 3}$ & $C_{3}$ & $R_{32}$ \\
\hline B-400 & 3.36 & 5.35 & 0.934 & -0.18 & 22.5 & -0.219 & 0.15 & 20.9 & 0.806 \\
AB-600 & 6.11 & 12.5 & 0.980 & 1.51 & 32.9 & 0.748 & 0.81 & 44.3 & 0.843 \\
AB-700 & 32.4 & 92.8 & 0.881 & 8.94 & 167.1 & 0.985 & 0.79 & 263.8 & 0.972 \\
AB-800 & 15.1 & 108.8 & 0.812 & 3.27 & 189.6 & 0.973 & 1.99 & 198.9 & 0.871 \\
AB-900 & 3.17 & 107.3 & 0.995 & 1.99 & 128.9 & 0.975 & 0.48 & 156.5 & 0.605
\end{tabular}



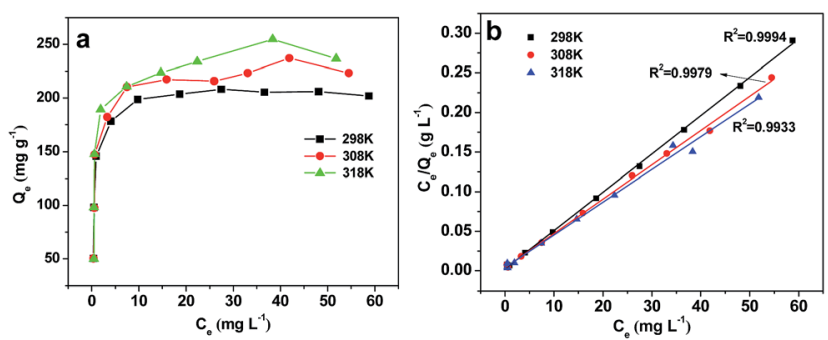

Fig. 7 Adsorption isotherms of CBZ at different temperature and the corresponding Langmuir isotherms.

demonstrating that the adsorption of $\mathrm{CBZ}$ is favorable at a higher temperature, and Fig. $7 \mathrm{~b}$ shows the corresponding linear fitting results by Langmuir model.

The thermodynamic parameters including standard free energy change $\left(\Delta G^{0}, \mathrm{~kJ} \mathrm{~mol}{ }^{-1}\right)$, standard enthalpy change $\left(\Delta H^{0}, \mathrm{~kJ} \mathrm{~mol}^{-1}\right)$ and standard entropy $\left(\Delta S^{0}, \mathrm{~J} \mathrm{~mol}^{-1} \mathrm{~K}^{-1}\right)$ were calculated using eqn (11) and (12).

$$
\begin{aligned}
& \ln K_{\mathrm{d}}=\frac{\Delta S^{0}}{R}-\frac{\Delta H^{0}}{R T} \\
& \Delta G^{0}=-R T \ln K_{\mathrm{d}}
\end{aligned}
$$

where $R\left(8.3145 \mathrm{~J} \mathrm{~mol}^{-1} \mathrm{~K}^{-1}\right)$ is the ideal gas constant, and $T(\mathrm{~K})$ is the temperature. $K_{\mathrm{d}}$ is the thermodynamic equilibrium constant, which calculated by plotting $\ln \left(Q_{\mathrm{e}} / C_{\mathrm{e}}\right) v s$. $Q_{\mathrm{e}}$ and extrapolating to zero $Q_{\mathrm{e}}{ }^{41,42}$ The values of $\Delta H^{0}$ and $\Delta S^{0}$ can be directly obtained from the slope and intercept of the plot ln $K_{\mathrm{d}}$ as a function of $10^{3} / T$ of linear (Fig. S5 $\dagger$ ).

Thermodynamic parameters of CBZ adsorption on AB-700 is shown in Table 7. The Gibbs free energy $\left(\Delta G^{0}\right)$ is negative, indicating that the adsorption process is spontaneous, ${ }^{43}$ which is consistent with the adsorption isotherms shown in the Fig. 7a. The absolute value of $\Delta G^{0}$ increases at higher temperature, which suggested that the driving force of adsorption and the affinity between CBZ and sorbent increased with increasing temperature. The enthalpy change $\Delta H^{0}\left(11.59 \mathrm{~kJ} \mathrm{~mol}^{-1}\right)>0$ indicates that the adsorption process is endothermic, and when $\left|\Delta H^{0}\right|<20 \mathrm{~kJ} \mathrm{~mol}^{-1}$, the adsorption process belongs to physical adsorption. ${ }^{44} \Delta S\left(95.64 \mathrm{~J} \mathrm{~mol}^{-1}\right.$ $\mathrm{K}^{-1}$ ) $>0$ indicates that the adsorption process is the process of free increase of entropy. The increased system chaos suggests that the structure of the sorbent significantly changed, which indicates that CBZ is easily adsorbed onto AB-700 but difficult to desorb from the sorbent.

Table 7 Thermodynamic parameter of CBZ adsorption on AB-700

\begin{tabular}{llll}
\hline $\begin{array}{l}\text { Temperature } \\
(\mathrm{K})\end{array}$ & $\begin{array}{l}\Delta G^{0} \\
\left(\mathrm{~kJ} \mathrm{~mol}^{-1}\right)\end{array}$ & $\begin{array}{l}\Delta H^{0} \\
\left(\mathrm{~kJ} \mathrm{~mol}^{-1}\right)\end{array}$ & $\begin{array}{l}\Delta S^{0} \\
\left(\mathrm{~J} \mathrm{~mol}^{-1} \mathrm{~K}^{-1}\right)\end{array}$ \\
\hline 298 & -17.65 & 11.59 & 95.64 \\
308 & -17.85 & & \\
318 & -18.05 & &
\end{tabular}

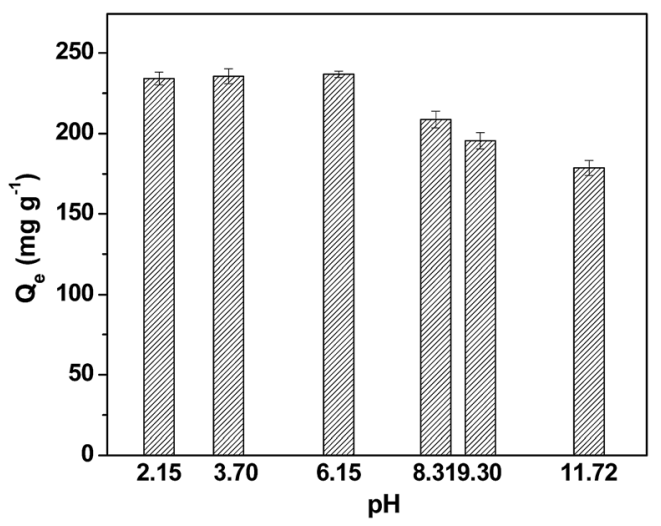

Fig. 8 The effect of $\mathrm{pH}$ on the adsorption of $\mathrm{CBZ}$ onto $\mathrm{AB}-700$ at 298 K.

\subsection{Effect of pH on adsorption}

The solution $\mathrm{pH}$ is a key factor in any adsorption process. The adsorption capacities of $\mathrm{CBZ}$ with different $\mathrm{pH}$ values are shown in Fig. 8. It was observed that the adsorption capacity of CBZ slightly increases (from 234.2 to $236.7 \mathrm{mg} \mathrm{g}^{-1}$ ) with the increase of $\mathrm{pH}$ value (from 2.15 to 6.15 ) at acid, and then gradually reduces (from 236.7 to $178.7 \mathrm{mg} \mathrm{g}^{-1}$ ) when the $\mathrm{pH}$ increases from 6.15 to 11.72 . This trend is consistent with the adsorption of CBZ onto graphene and carbon nanotubes. ${ }^{45}$ In addition, Ncibi et al. ${ }^{17}$ reported that the sorption of the CBZ on mesoporous activated carbons and multi-walled carbon nanotubes increased as the $\mathrm{pH}$ increased from 2 to 6 but decreased as the $\mathrm{pH}$ increased from 6 to 10. Brar et al. ${ }^{11}$ also reported that the sorption of CBZ on pine-wood derived nanobiochar gradually increased as the $\mathrm{pH}$ increased from 2 to 6 . When the solution $\mathrm{pH}$ is less than $\mathrm{pH}_{\mathrm{zpc}}$, the adsorbent surface has a positive charge with the proton $\mathrm{H}^{+}$. When the $\mathrm{pH}$ of the solution is greater than the $\mathrm{pH}_{\mathrm{zpc}}$ value, the adsorbent surface is negatively charged with the $\mathrm{OH}^{-}$. The larger the $\mathrm{pH}_{\mathrm{zpc}}$, the more positive on the surface of the adsorbent, the stronger the attraction to the anion, and the stronger the repulsion. The $\mathrm{pH}_{\mathrm{zpc}}$ of $\mathrm{AB}-700$ is 4.46 (Fig. S6 + ), which indicates that the surface of the $\mathrm{AB}-700$ is positive at the solution $\mathrm{pH}<4.46$, otherwise the surface of the $\mathrm{AB}-700$ is negative at the solution $\mathrm{pH}>4.46$. Under the investigated $\mathrm{pH}$ range (2.15 to 11.72 ), $\mathrm{CBZ}$ molecules remained unchanged, leading to a low electrostatic attraction with the charged AB-700. Therefore, the adsorption of CBZ onto AB-700 may be mainly controlled by hydrophobic, $\pi-\pi$ interactions and hydrogen bonding.

\subsection{Effect of ionic strength and reuse of sorbent}

The effects of ionic strength on CBZ adsorption onto AB-700 are presented in Fig. 9a. We can see that the adsorption capacity of CBZ onto AB-700 is stable in the presence of 0.005 and $0.01 \mathrm{M}$ of $\mathrm{Na}^{+}$ions. When the concentration of $\mathrm{Na}^{+}$ions was increased to 0.015 and $0.02 \mathrm{M}$, the adsorption capacity of CBZ onto AB-700 showed a slight decrease. It indicates that the effect of ionic strength is weak on the adsorption of CBZ. 

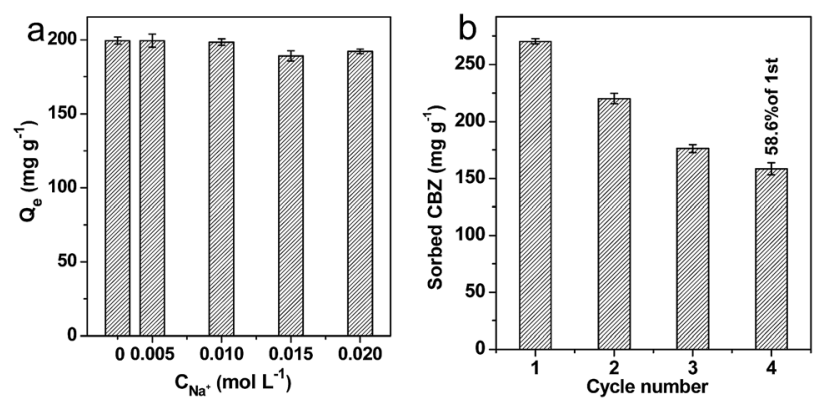

Fig. 9 (a) Effect of ionic strength on $C B Z$ adsorption onto $A B-700$, and (b) reuse of $A B-700$.

To evaluate the possibility of regeneration and reusability of the AB-700 for practical application, the reuse of sorbent was performed and shown in Fig. 9b. According to the TG curve of CBZ (Fig. S1 $\dagger$ ), the sorbent after adsorption of CBZ was cycled using the heat-treatment method. Fig. $9 \mathrm{~b}$ shows that the AB-700 still delivered an adsorption capacity of $158.4 \mathrm{mg} \mathrm{g}^{-1}$ for CBZ at the $4^{\text {th }}$ cycle, which is $58.6 \%$ of the initial adsorption. Considering the residual of thermal decomposition of $\mathrm{CBZ}$ on the surface of $\mathrm{AB}-700$, we believe that as-prepared $\mathrm{AB}-700$ is a great and reversible efficient adsorbent in potential practical application for wastewater treatment.

\subsection{Adsorption mechanisms}

Hydrophobic interaction may play an important role in the adsorption of CBZ on as-prepared biochar. Generally, the octanol-water distribution coefficient $\left(K_{\text {ow }}\right)$ of organic pollutants can be used to predict the hydrophobic interaction between adsorbates and adsorbents, and high $K_{\text {ow }}$ indicates high hydrophobic interaction. However, the $K_{\mathrm{ow}}$ of CBZ is only 2.45 , suggesting that $\mathrm{CBZ}$ is relatively hydrophilic. Obviously, the weak hydrophobic interaction cannot explain the high adsorption capacity of CBZ onto AB-700. Therefore, the dominant role of hydrophobic effects can be excluded.

Hydrogen bond may form between functional groups (such as $\mathrm{COOH}, \mathrm{OH}$ and $\mathrm{NH}_{2}$ ) of aromatic compounds and activated biochar. With the increase of solution $\mathrm{pH}$ value, the concentration of $\mathrm{H}^{+}$reduced, and the hydrogen bonding donor groups on CBZ can interact with hydrogen bonding acceptors or $\pi$ donors in $\mathrm{AB}-700$ and therefore the adsorption efficiency was enhanced. However, when the solution was changed to alkaline, the adsorption of CBZ onto AB-700 decreased. Therefore, hydrogen bond was not the predominant factor to control the adsorption of CBZ in this study.

$\pi-\pi$ electron donor-acceptor (EDA) interaction is specific and noncovalent, that exists between electron-rich and electronpoor compounds widely. ${ }^{46}$ The possibility of $\pi-\pi$ EDA interaction has been considered in the adsorption of aromatic compounds to carbon materials. Generally, donor strength increases with the $\pi$-system polarizability or electron-donating ability of substitutes, and acceptor strength depends on the electron-withdrawing ability and the number of substitutes. ${ }^{47}$ The activated biochar is a strongly $\pi$-donor because of these $\pi$ -
Table 8 Content of elements (atomic\%) on the surface AB-700 before and after adsorbed $\mathrm{CBZ}$, and $\mathrm{CBZ}$

\begin{tabular}{llll}
\hline Sample & Carbon\% & Oxygen\% & Nitrogen\% \\
\hline AB-700 & 93.04 & 5.79 & 1.17 \\
AB-700/CBZ & 90.57 & 7.63 & 1.79 \\
CBZ & 84.69 & 5.44 & 9.87
\end{tabular}
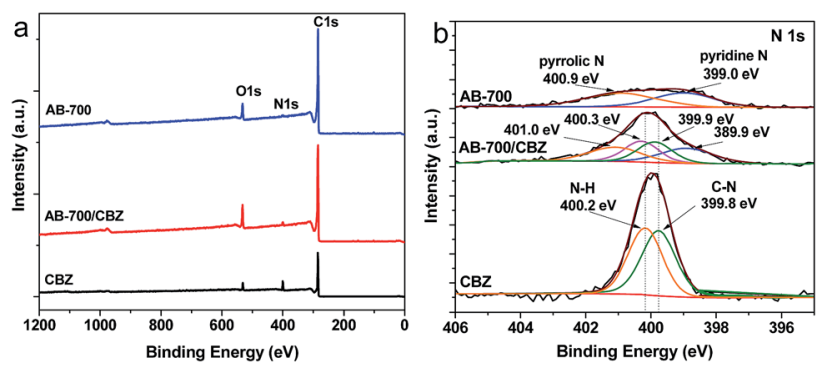

Fig. 10 XPS spectra of pristine AB-700, those adsorbed CBZ and pristine CBZ. (a) Full-view, (b) N 1s.

electron donor groups include the aromatic benzene rings and electron-rich $\mathrm{OH}$. CBZ can be act as a $\pi$-electron acceptor due to the electron withdrawing capability of the amide group, whose $\mathrm{N}$ atom, along with the heterocyclic ring $\mathrm{N}$, is in $\mathrm{sp}^{2}$ configurations with their lone pairs of electrons delocalized in bonds with the electron-withdrawing carbonyl group..$^{15}$ Therefore, $\pi-\pi$ electron donor-acceptor (EDA) interaction has been proposed to be the primary mechanism for the adsorption of CBZ onto activated biochar. Finally, the change trend of CBZ adsorption onto AB-700 may be attributed to that the $\pi-\pi$ EDA interactions between sorbate-sorbent are sensitive to $\mathrm{pH}$ of solution.

To further support the adsorption mechanism discussed above, the XPS analysis of the initial AB-700 and the those with adsorbed CBZ were carried out, and shown in Fig. 10. The elemental compositions (atomic\%) on our AB-700 and pristine CBZ are presented in Table 8. C is the main element (93.04\%) on the surface of $\mathrm{AB}-700$, and $5.79 \%$ of $\mathrm{O}$ presents in the form of $\mathrm{C}=\mathrm{O}$ and $\mathrm{C}-\mathrm{O}$. In addition, $1.17 \%$ of $\mathrm{N}$ comes from the nature of pomelo peel. After adsorption of $\mathrm{CBZ}$, the atomic\% of $\mathrm{O}$ and $\mathrm{N}$ on $\mathrm{AB}-700$ increases to 7.63 and $1.79 \%$, respectively. According to the atomic ratio of $\mathrm{O}$ in $\mathrm{CBZ}$ molecule, the increased ratio of $\mathrm{O}$ might come from the adsorbed carbon dioxide on the AB-700. Fig. 10b shows the high-resolution $\mathrm{N}$ 1s spectra. The N 1s spectrum of AB-700 can be deconvoluted into two peaks at 399.0 and $400.9 \mathrm{eV}$, which are assigned to pyridinic-like, and pyrrolic-like $\mathrm{N}$, respectively. The $\mathrm{N}$ 1s spectrum of pure CBZ shows two peak components at 399.8 and $400.2 \mathrm{eV}$, corresponding to the $\mathrm{C}-\mathrm{N}$ and $\mathrm{N}-\mathrm{H}$ in $\mathrm{CBZ}$ molecule, respectively. The $\mathrm{N} 1 \mathrm{~s}$ of $\mathrm{AB}-700 / \mathrm{CBZ}$ indicates the overlay of $\mathrm{AB}-$ 700 and pure CBZ, but all four peaks of $\mathrm{N}$ have a slight shift, which reveals the influence on outer electron cloud density of $\mathrm{N}$ atoms due to interaction between adsorbent and adsorbate. Notably, the peaks of C-N and N-H in CBZ shifts to 399.9 and $400.3 \mathrm{eV}$, respectively, which can be attributed to the $\pi-\pi$ EDA 
interaction between $\mathrm{AB}-700$ and $\mathrm{CBZ}$. The $\pi$-electron donor groups on the surface of $\mathrm{AB}-700$ can increase the electron cloud density of $\mathrm{N}$ atoms in $\mathrm{CBZ}$ molecule, resulting in the weak increase of binding energy of $\mathrm{C}-\mathrm{N}$ and $\mathrm{N}-\mathrm{H}$ in $\mathrm{CBZ}$.

\section{Conclusions}

In summary, activated biochars were successfully synthesized through the carbonization of pomelo peel and further $\mathrm{KOH}$ activation. The characterizations showed that the activation temperature can significantly influence the microstructure and surface chemistry of these activated biochars. The adsorption properties of these activated biochars were investigated by the removal of CBZ from aqueous solution, and the results showed that the behaviors of CBZ onto these activated biochars were fitted well by Langmuir and pseudo-second-order kinetic models, and the adsorption was mainly physisorption and controlled by the intra-particle diffusion. In addition, the adsorption of CBZ onto the as-prepared activated biochars were influenced by the pore structure and surface functional groups, and the activated biochar showed a higher adsorption capacity of CBZ up to $286.5 \mathrm{mg} \mathrm{g}^{-1}$. The thermodynamic analysis revealed that the adsorption of $\mathrm{CBZ}$ onto activated biochar (AB-700) were spontaneous and exothermic. The analysis of adsorption mechanism suggested that the adsorption of CBZ onto activated biochar was mainly dominated by $\pi-\pi$ electron donor-acceptor interaction.

\section{Conflicts of interest}

There are no conflicts to declare.

\section{Acknowledgements}

We gratefully acknowledge the generous support by the National Nature Science Fund of China (Grant No. 51402146), the National Science Fund for Excellent Young Scholars of China (Grant No. 51422807), the Natural Science Foundation (Grant No. 20171BAB206046) of Jiangxi Province, the Science and Technology Planning Project (Grant No. 20151BBG70019) of Jiangxi Province, and the Foundation (Grant No. DA201602064) from the Educational Commission of Jiangxi Province. Additionally, a GanPo 555 Talent Project funded by Jiangxi Province is also appreciated.

\section{Notes and references}

1 J.-L. Liu and M.-H. Wong, Environ. Int., 2013, 59, 208-224.

2 Y. Zhang, S. U. Geissen and C. Gal, Chemosphere, 2008, 73, 1151-1161.

3 X. Yuan, Z. Qiang, W. Ben, B. Zhu and J. Qu, Environ. Sci.: Processes Impacts, 2015, 17, 596-605.

4 B. t. Ferrari, N. Paxéus, R. L. Giudice, A. Pollio and J. Garric, Ecotoxicol. Environ. Saf., 2003, 55, 359-370.

5 A. Dal Pozzo, G. Donzelli, L. Rodriquez and A. Tajana, Int. J. Pharm., 1989, 50, 97-101.
6 V. Calisto, M. R. M. Domingues, G. L. Erny and V. I. Esteves, Water Res., 2011, 45, 1095-1104.

7 A. Almeida, V. Calisto, V. I. Esteves, R. J. Schneider, A. M. Soares, E. Figueira and R. Freitas, Aquat. Toxicol., 2014, 156, 74-87.

8 A. Jelic, M. Gros, A. Ginebreda, R. Cespedes-Sánchez, F. Ventura, M. Petrovic and D. Barcelo, Water Res., 2011, 45, 1165-1176.

9 L. Nielsen, M. J. Biggs, W. Skinner and T. J. Bandosz, Carbon, 2014, 80, 419-432.

10 J. Chen, D. Zhang, H. Zhang, S. Ghosh and B. Pan, Sci. Total Environ., 2017, 579, 598-605.

11 M. Naghdi, M. Taheran, R. Pulicharla, T. Rouissi, S. K. Brar, M. Verma and R. Y. Surampalli, Arabian J. Chem., 2017, DOI: 10.1016/j.arabjc.2016.12.025.

12 S. Komtchou, A. Dirany, P. Drogui and A. Bermond, Environ. Sci. Pollut. Res., 2015, 22, 11513-11525.

13 L. Tang, J.-j. Wang, C.-t. Jia, G.-x. Lv, G. Xu, W.-t. Li, L. Wang, J.-y. Zhang and M.-h. Wu, Appl. Catal., B, 2017, 205, 587-596.

14 D. Fatta-Kassinos, M. I. Vasquez and K. Kummerer, Chemosphere, 2011, 85, 693-709.

15 N. Cai and P. Larese-Casanova, J. Colloid Interface Sci., 2014, 426, 152-161.

16 P. Oleszczuk, B. Pan and B. Xing, Environ. Sci. Technol., 2009, 43, 9167-9173.

17 M. C. Ncibi and M. Sillanpää, J. Mol. Liq., 2017, 238, 379-388. 18 W. Zhang, Y. Ding, S. A. Boyd, B. J. Teppen and H. Li, Chemosphere, 2010, 81, 954-960.

19 Y. L. Zhang, J. Zhang, C. M. Dai, X. F. Zhou and S. G. Liu, Carbohydr. Polym., 2013, 97, 809-816.

20 C. Wang, H. Li, S. Liao, H. Zheng, Z. Wang, B. Pan and B. Xing, Carbon, 2013, 65, 243-251.

21 L. Hadjittofi, M. Prodromou and I. Pashalidis, Bioresour. Technol., 2014, 159, 460-464.

22 G. X. Yang and H. Jiang, Water Res., 2014, 48, 396-405.

23 H. Jin, S. Capareda, Z. Chang, J. Gao, Y. Xu and J. Zhang, Bioresour. Technol., 2014, 169, 622-629.

24 S. Dawood, T. K. Sen and C. Phan, Bioresour. Technol., 2017, 246, 76-81.

25 L. Lin, W. Jiang and P. Xu, Sci. Total Environ., 2017, 601-602, 857-864.

26 J. Deng, Y. Liu, S. Liu, G. Zeng, X. Tan, B. Huang, X. Tang, S. Wang, Q. Hua and Z. Yan, J. Colloid Interface Sci., 2017, 506, 355-364.

27 Y. Dong, W. Wang, H. Quan, Z. Huang, D. Chen and L. Guo, ChemElectroChem, 2016, 3, 814-821.

28 W. Wang, H. Quan, W. Gao, R. Zou, D. Chen, Y. Dong and L. Guo, RSC Adv., 2017, 7, 16678-16687.

29 M. Kumar, B. P. Tripathi and V. K. Shahi, J. Hazard. Mater., 2009, 172, 1041-1048.

30 Z. Zawani, A. Chuah and T. Choong, Eur. J. Sci. Res., 2009, 37, 67-76.

31 C. O. Ania and T. J. Bandosz, Langmuir, 2005, 21, 7752-7759. 32 M. Baghdadi, E. Ghaffari and B. Aminzadeh, J. Environ. Chem. Eng., 2016, 4, 3309-3321.

33 M.-H. To, P. Hadi, C.-W. Hui, C. S. K. Lin and G. McKay, J. Mol. Liq., 2017, 241, 386-398. 
34 D. Shan, S. Deng, T. Zhao, B. Wang, Y. Wang, J. Huang, G. Yu, J. Winglee and M. R. Wiesner, J. Hazard. Mater., 2016, 305, 156-163.

35 N. Cai and P. Larese-Casanova, J. Colloid Interface Sci., 2014, 426, 152-161.

36 D. A. Borisova, M. D. Vedenyapina, E. D. Strel'tsova, V. L. Maslov, K. H. Rosenwinkel, D. Weichgrebe, P. Stopp and A. A. Vedenyapin, Solid Fuel Chem., 2013, 47, 298-302.

37 D. Chen, C. Chen, W. Shen, H. Quan, S. Chen, S. Xie, X. Luo and L. Guo, Adv. Powder Technol., 2017, 28, 1769-1779.

38 G. Chu, J. Zhao, F. Chen, X. Dong, D. Zhou, N. Liang, M. Wu, B. Pan and C. E. W. Steinberg, Environ. Pollut., 2017, 227, 372-379.

39 F. F. Liu, J. Zhao, S. Wang, P. Du and B. Xing, Environ. Sci. Technol., 2014, 48, 13197-13206.
40 S. K. Singh, T. G. Townsend, D. Mazyck and T. H. Boyer, Water Res., 2012, 46, 491-499.

$41 \mathrm{~J}$. Wu and H. Q. Yu, J. Hazard. Mater., 2006, 137, 498-508.

42 Y. Xi, Y. Luo, J. Luo and X. Luo, J. Chem. Eng. Data, 2015, 60, 3253-3261.

43 H. Gu, H. Lou, J. Tian, S. Liu and Y. Tang, J. Mater. Chem. A, 2016, 4, 10174-10185.

44 M. Alkan, O. Demirbas, S. Celikcapa and M. Dogan, J. Hazard. Mater., 2004, 116, 135-145.

45 F.-f. Liu, J. Zhao, S. Wang, P. Du and B. Xing, Environ. Sci. Technol., 2014, 48, 13197-13206.

46 C. A. Hunter and J. K. M. Sanders, J. Am. Chem. Soc., 1990, 112, 5525-5534.

47 W. Chen, L. Duan and D. Zhu, Environ. Sci. Technol., 2007, 41, 8295-8300. 